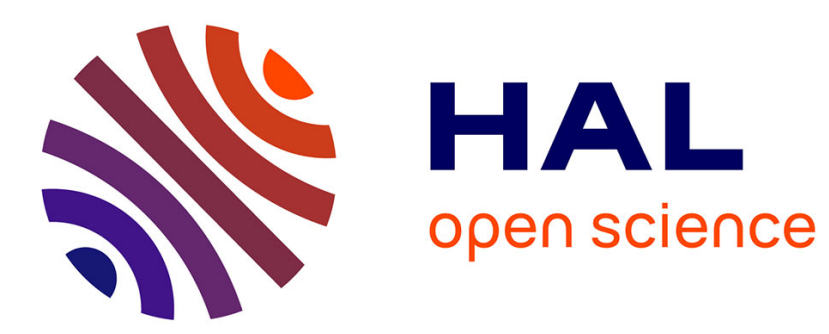

\title{
Error evaluation on experimental stress-strain curve obtained from tube bulging test
}

\author{
Abdel Hakim Ben Ouirane, Raphaël Velasco, Gérard Michel, Nathalie
} Boudeau

\section{- To cite this version:}

Abdel Hakim Ben Ouirane, Raphaël Velasco, Gérard Michel, Nathalie Boudeau. Error evaluation on experimental stress-strain curve obtained from tube bulging test. International Journal of Material Forming, 2011, 3, pp.195-198. 10.1007/s12289-010-0740-1 . hal-02300116

\section{HAL Id: hal-02300116 https://hal.science/hal-02300116}

Submitted on 20 Nov 2019

HAL is a multi-disciplinary open access archive for the deposit and dissemination of scientific research documents, whether they are published or not. The documents may come from teaching and research institutions in France or abroad, or from public or private research centers.
L'archive ouverte pluridisciplinaire HAL, est destinée au dépôt et à la diffusion de documents scientifiques de niveau recherche, publiés ou non, émanant des établissements d'enseignement et de recherche français ou étrangers, des laboratoires publics ou privés. 


\title{
ERROR EVALUATION ON EXPERIMENTAL STRESS-STRAIN CURVE OBTAINED FROM TUBE BULGING TEST
}

\author{
Abdel Hakim Ben Ouirane ${ }^{1}$, Raphaël Velasco ${ }^{3}$, Gérard Michel ${ }^{1,2}$, Nathalie Boudeau ${ }^{1,2}$ \\ ${ }^{1}$ FEMTO-ST - Dpt of Applied Mechanics, 24 rue de l'Epitaphe, 25000 Besançon, France \\ ${ }^{2}$ ENSMM Besançon, 26 rue de l'Epitaphe, 25030 Besançon Cedex, France \\ ${ }^{3}$ IUT GMP, avenue des facultés, Le Bailly, 80025 Amiens cedex 1, France
}

\begin{abstract}
The paper is focused on a sensitivity analysis developed to study the relevance of experimental hardening curves obtained from tube bulging test to quantify the influence and the contribution of experimental uncertainties on the response variability. The experiments are based on "online" measurements of the internal pressure and the bulge height. A semi analytical model developed from a geometrical representation of the bulged tube and equilibrium of infinitesimal volumes (slab method) permits to evaluate the stress-strain curve. The differentiation of all the equations of the model and the evaluation of all the input parameters allow to get the total uncertainty on the resulting hardening curve and to identify the critical experimental parameters. Hence the results of this sensitivity analysis open up ways of improvements for conducting experimental tube bulging test.
\end{abstract}

KEYWORDS: bulging test; semi-analytical model, hardening curve, error calculation

\section{INTRODUCTION}

Tube hydroforming process presents a great interest for industrial applications. It permits to obtain complex hollow shaped parts with reduced number of welding spots and higher quality [1-3]. In order to conduct predictive simulations of the hydroforming process, material parameters directly measured on tube must be preferred. To characterize precisely tubular material behavior, tube bulging test is applied It consists in bulging a tube over an area defined by the tool by applying an internal pressure. The identification of the hardening curve of a given tube and the estimation of its formability needs a specific experimental device coupled with a mathematical model. Hwang and al propose in [4] a methodology to determine the hardening of a tubular material whereas stretching tube is not uniform and the contact between the die and the tube is sticking. By comparing the experimental results obtained by a free bulging of two tubes, a tensile test on the same classic shapes of tubes and data obtained from Fuchizawa's analytical model [5] they demonstrated the relevance of bulging test. Spisak and Slota have shown in [6] that the test of bulging better describe the mechanical properties at large plastic deformations, in particular for cold rolled sheets and tubes. Both authors justify the use of this test to identify difficulties related to the strain hardening behaviour of a material, since the rate of uniform and stable deformation in a conventional tensile test is limited to half the limit of fracture under a biaxial load. The construction of any mathematical model is subject to two sources of uncertainties: epistemic uncertainties, partly due to the impossibility of knowing perfectly the problem studied, and random uncertainties due to the fact that certain parameters of the deterministic model are estimated by mean values of random variables. In order to find out how our model answers back to input factors, a local sensitivity study is performed to investigate the effects of various bulging parameters upon the strain and stress states. The physical parameters in question are mainly the initial thickness of the tube, the initial outer radius, the position of the displacement sensor, the bulge length, the bulge height and pressure in the tube. Different methods of differentiation can be used to form the sensitivity matrix. In the present case there are more input parameters than outputs and an analytical differentiation is then chosen.

\section{SEMI-ANALYTICAL MODEL}

The model is based on the geometrical description given below in Figure 1 and the following assumptions:

\footnotetext{
* Nathalie Boudeau: ENSMM, 26 Rue de l'Epitaphe, 25030 Besançon cedex, France, +33(0)381666 034, +33(0)381666 700, nathalie.boudeau@ens2m.fr
} 
- Strain and stress tensors are diagonal in the local frame $\left(\overrightarrow{\mathbf{e}_{\mathbf{r}}}, \overrightarrow{\mathbf{e}_{\boldsymbol{\theta}}}, \overrightarrow{\mathbf{e}_{\boldsymbol{\phi}}}\right)$.

- Plane stress condition is considered.

- Elastic deformations are insignificant.

- Axial symmetry is conserved during the bulge test.

- $(\mathrm{X}, \mathrm{Y})$ is a symmetry plane.

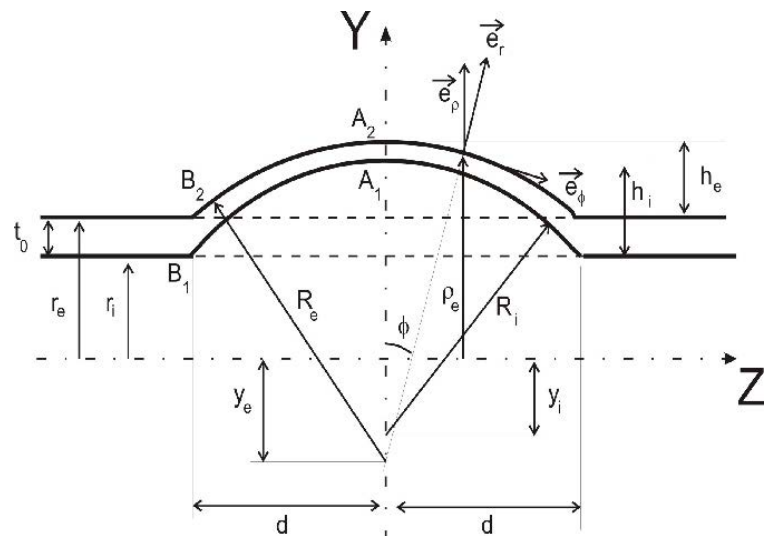

Figure 1: Geometric model for tube bulging test analysis and definition of the parameters

The approach is based on "on-line' measurements and doesn't need FE results. Only the internal pressure and the bulge height at the pole are measured during the test. The main steps of the modelling are described below but more details can be found in [7].

\subsection{ASSUMPTIONS}

The model is devoted to quantify the stress-strain couple during a thin tube bulging test so plane stress assumption can be done. The axial symmetry of the initial tube and the loading (internal pressure) permits to affirm that the principal directions are the normal to the tube surface and the two tangential directions. In this set of axes, the strain and stress tensors can be expressed as following:

$\underline{\boldsymbol{\varepsilon}}=\left(\begin{array}{ccc}\boldsymbol{\varepsilon}_{\mathrm{rr}} & 0 & 0 \\ 0 & \boldsymbol{\varepsilon}_{\boldsymbol{\theta} \boldsymbol{\theta}} & 0 \\ 0 & 0 & \boldsymbol{\varepsilon}_{\boldsymbol{\phi \phi}}\end{array}\right)$ and $\underline{\boldsymbol{\sigma}}=\left(\begin{array}{ccc}0 & 0 & 0 \\ 0 & \boldsymbol{\sigma}_{\boldsymbol{\theta}} & 0 \\ 0 & 0 & \boldsymbol{\sigma}_{\boldsymbol{\phi} \boldsymbol{\phi}}\end{array}\right)$

\subsection{GEOMETRIC RELATIONS}

Various parameters used in the geometric model are listed in Table 1.

The internal pressure " $p$ " and bulge height " $h_{\mathrm{e}}$ " at the pole are measured continuously using respectively a pressure sensor and a linear potentiometer. Relations between the geometrical parameters can be established and are detailed in [7].

\section{Table 1: List of the model parameters}

\begin{tabular}{|c|c|}
\hline \multicolumn{2}{|c|}{ TOOL } \\
\hline $2 \mathrm{~d}$ & Length of the free bulge zone of the tube \\
\hline \multicolumn{2}{|c|}{ TUBE } \\
\hline $\mathrm{t}_{0}$ & Initial thickness of the tube \\
\hline $\mathrm{r}_{\mathrm{q}}$ & Initial radius of the tube \\
\hline \multicolumn{2}{|c|}{ MODEL } \\
\hline $\mathrm{h}_{\mathrm{q}}$ & Bulge height of the tube at the pole \\
\hline $\mathrm{R}_{\mathrm{q}}$ & $\begin{array}{l}\text { Current radius of the bulged tube in the } \\
(\mathrm{Y}, \mathrm{Z}) \text { plane }\end{array}$ \\
\hline$\rho_{\mathrm{q}}$ & $\begin{array}{l}\text { Current radius of the bulged tube in the } \\
(\mathrm{X}, \mathrm{Z}) \text { plane }\end{array}$ \\
\hline $\mathrm{y}_{\mathrm{q}}$ & $\begin{array}{l}\text { Distance between the centre of the } \\
\text { curvature and the tube axis in }(\mathrm{Y}, \mathrm{Z})\end{array}$ \\
\hline$\varphi$ & $\begin{array}{l}\text { Angle for referring the point in the length } \\
\text { of the tube when deformed }\end{array}$ \\
\hline \multicolumn{2}{|c|}{ INDICE } \\
\hline $\mathrm{q}$ & $\begin{array}{l}\mathrm{q}=\text { "e" stands for external and } \mathrm{q}=\text { "i" } \\
\text { stands for internal }\end{array}$ \\
\hline
\end{tabular}

\subsection{MECHANICAL ANALYSIS}

Strains can be calculated by the following equations:

$$
\begin{gathered}
\varepsilon_{\mathbf{r r}}=\ln \left(\frac{\mathbf{t}(\mathbf{z})}{\mathbf{t}_{0}}\right)=\ln \left(\frac{\mathbf{t}(\phi)}{\mathbf{t}_{0}}\right) \\
\varepsilon_{\theta \boldsymbol{\theta}}=\ln \left(\frac{\rho_{\mathrm{e}}(\mathbf{z})}{\mathbf{r}_{\mathrm{e}}}\right)=\ln \left(\frac{\rho_{\mathrm{e}}(\phi)}{\mathbf{r}_{\mathrm{e}}}\right) \\
\varepsilon_{\phi \phi}=-\varepsilon_{\mathrm{rr}}-\varepsilon_{\theta \theta}
\end{gathered}
$$

Equation (3) corresponds to the plastic incompressibility condition.

Then effective strain is obtained using hoop and radial strains:

$$
\bar{\varepsilon}=\frac{2}{\sqrt{3}} \cdot \sqrt{\left(\varepsilon_{\mathrm{rr}}\right)^{2}+\left(\varepsilon_{\theta \theta}\right)^{2}+\varepsilon_{\mathrm{rr}} \cdot \varepsilon_{\theta \theta}}
$$

The stress components can be found from slab method by studying the local equilibrium of two infinitesimal tube parts loaded with an internal pressure $p$. Then it can be found that:

$$
\begin{gathered}
\sigma_{\theta \theta}=\frac{\mathbf{p} \cdot \boldsymbol{\rho}(\phi)}{\mathbf{t}(\phi) \cdot \cos \phi} \cdot\left[1-\frac{\rho(\phi)}{\mathbf{R} \cdot \cos \phi}\right] \\
\sigma_{\phi \phi}=\frac{\mathbf{p} \cdot \boldsymbol{\rho}(\phi)}{2 \cdot \mathbf{t}(\phi) \cdot \cos \phi}
\end{gathered}
$$


And the equivalent stress is equal to:

$$
\bar{\sigma}=\sqrt{\left(\sigma_{\theta \theta}\right)^{2}+\left(\sigma_{\phi \phi}\right)^{2}-\sigma_{\theta \theta} \cdot \sigma_{\phi \phi}}
$$

\section{SENSITIVITY ANALYSIS}

Sensitivity analysis helps to build confidence in the model by studying the uncertainties that are often associated with parameters in model.

\subsection{TECHNICS}

The proposed semi-analytical model is based on geometric data and measurements. All input data present inaccuracy and it is important to know how uncertainties contribute to the final imprecision on the resulting $(\sigma, \varepsilon)$ couple. We attempt to determine the parameters that contribute the most on the variability of the outputs i.e. stress and strains, and whether certain factors interact.

Let note with Greek letters measured data (such as pressure and dome height), with small Latin letters imposed geometric data that stays constant during the test (like initial thickness, initial tube radius), with capital Latin letters all others parameters that present an evolution when the pressure increases in the tube (for example, the current thickness, the stresses and strains, but also any other intermediate parameters).

For some parameters, their relation with the others takes the following form:

$$
\mathbf{X}=\mathbf{X}(\boldsymbol{\alpha}, \mathbf{x})
$$

The differentiation of the equation above gives:

$$
\mathbf{d X}=\frac{\partial \mathbf{X}}{\partial \boldsymbol{\alpha}} \cdot \mathbf{d} \boldsymbol{\alpha}+\frac{\partial \mathbf{X}}{\partial \mathbf{x}} \cdot \mathbf{d x}
$$

The error done on X-parameter can be linked to the errors done on $\alpha$ and $\mathrm{x}$ :

$$
\Delta \mathbf{X}=\left|\frac{\partial \mathbf{X}}{\partial \alpha} \cdot\right| \Delta \alpha+\left|\frac{\partial \mathbf{X}}{\partial \mathbf{x}}\right| \cdot \Delta \mathbf{x}
$$

Often, the problem is expressed as following:

$$
\left\{\begin{array}{l}
\mathbf{X}=\mathbf{X}(\boldsymbol{\alpha}, \mathbf{Y}, \mathbf{x}) \\
\mathbf{Y}=\mathbf{Y}(\boldsymbol{\beta}, \mathbf{y})
\end{array}\right.
$$

In these conditions, the error on $\mathrm{X}$-parameter is expressed by:

$\Delta \mathbf{X}=\left|\frac{\partial \mathbf{X}}{\partial \boldsymbol{\alpha}}\right| \cdot \Delta \boldsymbol{\alpha}+\left|\frac{\partial \mathbf{X}}{\partial \mathbf{Y}} \cdot \frac{\partial \mathbf{Y}}{\partial \boldsymbol{\beta}}\right| \cdot \Delta \boldsymbol{\beta}+\left|\frac{\partial \mathbf{X}}{\partial \mathbf{Y}} \cdot \frac{\partial \mathbf{Y}}{\partial \mathbf{y}}\right| \cdot \Delta \mathbf{y}+\left|\frac{\partial \mathbf{X}}{\partial \mathbf{x}}\right| \cdot \Delta \mathbf{x}$

Sometimes there is an implicit relation between parameters like:

$\mathbf{f}(\boldsymbol{\alpha}, \mathbf{X}, \mathbf{x})=0$

In that case, the error on $\mathrm{X}$-parameter is expressed by Equation (12).

This will be applied with all the equations defining the model of section 2 by using Matlab® software.

$$
\Delta \mathbf{X} \approx \frac{|\Delta \mathbf{f}|+\left|\frac{\partial \mathbf{f}}{\partial \boldsymbol{\alpha}}\right| \cdot \Delta \boldsymbol{\alpha}+\left|\frac{\partial \mathbf{f}}{\partial \mathbf{x}}\right| \cdot \Delta \mathbf{x}}{\left|\frac{\partial \mathbf{f}}{\partial \mathbf{X}}\right|}
$$

\subsection{RESULTS AND DISCUSSION}

Experiments of tube bulging are the origin of several uncertainties. Some are due to the sensors precision like for the bulge height and internal pressure. Some are due to the experimental device like the length of bulged zone or the position of the LVDT sensor. Others are due to

\begin{tabular}{|c|c|c|c|}
\hline \multicolumn{4}{|c|}{ Characteristics of the bulged test } \\
\hline & Domain of variation & Error & Source \\
\hline $\mathrm{p}$ & $0-40 \mathrm{MPa}$ & $0.3 \%$ & Datasheet of \\
\hline $\mathrm{h}_{\mathrm{e}}$ & $0-8 \mathrm{~mm}$ & $0.02 \%$ & sensors \\
\hline \multicolumn{4}{|c|}{ Tube } \\
\hline & Nominal value & Error & Source \\
\hline$r_{e}$ & $17,5 \mathrm{~mm}$ & $1 \%$ & \multirow{2}{*}{ Tube supplier } \\
\hline$t_{0}$ & $1 \mathrm{~mm}$ & $10 \%$ & \\
\hline \multicolumn{4}{|c|}{ Tool } \\
\hline & Nominal value & Error & Source \\
\hline d & $25 \mathrm{~mm}$ & $5 \mathrm{~mm}$ & Machining \\
\hline $\mathrm{Z}$ & 0 & $5 \mathrm{~mm}$ & tolerances \\
\hline
\end{tabular}
inaccuracy of the tube geometry like the initial thickness and radius. Table 2 summarises the nominal dimensions or domain of variation for the main parameters with their associated errors.

Table 2: Nominal dimensions or domain of variation and associated errors of the main parameters

From equations of section 2.3 and the analysis presented in section 3.1, it is possible to quantify the resulting errors on equivalent strain and stress but also the critical sources of errors on the resulting hardening law.

The study has been conducted for the couple $(\overline{\boldsymbol{\varepsilon}}=0.45 ; \overline{\boldsymbol{\sigma}}=636 \mathrm{MPa})$. Figures 2 and 3 give the global error on the equivalent strain and stress and the contribution of each source of error.

Through this sensitivity analysis we can identify the most important factor. This is defined to be the one that, if determined, would lead to the greatest reduction in the variance of the effective strain and stress. In this case, imprecision on the initial thickness is the more critical for a good evaluation of the equivalent strain and stress. 


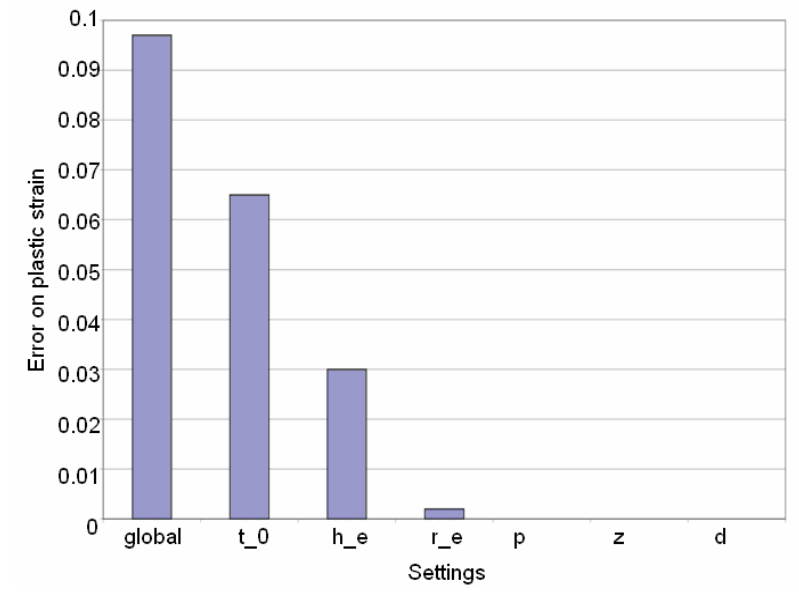

Figure 2: Global error and the different contributions on the equivalent strain calculated for $\overline{\boldsymbol{\varepsilon}}_{\text {nom }}=0.45$

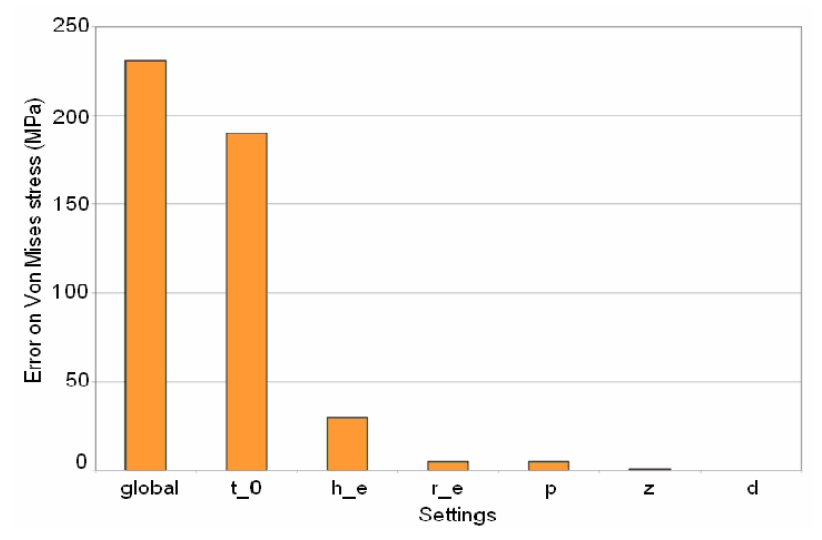

Figure 3: Global error and the different contributions on the equivalent stress calculated for $\overline{\boldsymbol{\sigma}}_{\text {nom }}=636 \mathrm{MPa}$

Likewise, we can define the second most important factor and so on till all factors are ranked in order of importance. In fact, the second important parameter is the bulge height which presents more influence on the quantification of the strain than the stress. The third important parameter is the uncertainty on the initial external radius of the tube with the same importance for strain and stress. The accuracy on the pressure value presents also an influence on the stress evaluation but its importance is quite weak. These results are in agreement with numerical results presented in [7] where several FE simulations were performed by changing only one parameter for each run. The resulting hardening laws are given in figure 4 where nominal law can be compared with its extreme laws obtained by FE simulations and the differentiation of the semi-analytical model.

\section{CONCLUSIONS}

These results lead to the following conclusions:

- The quality of the tube is important to get exploitable data for the hardening law and it is necessary to know exactly the imprecision on the initial thickness and radius of the tube to be tested.
- It is important to use precise LVDT and pressure sensors to measure respectively the height of bulge and the internal pressure.

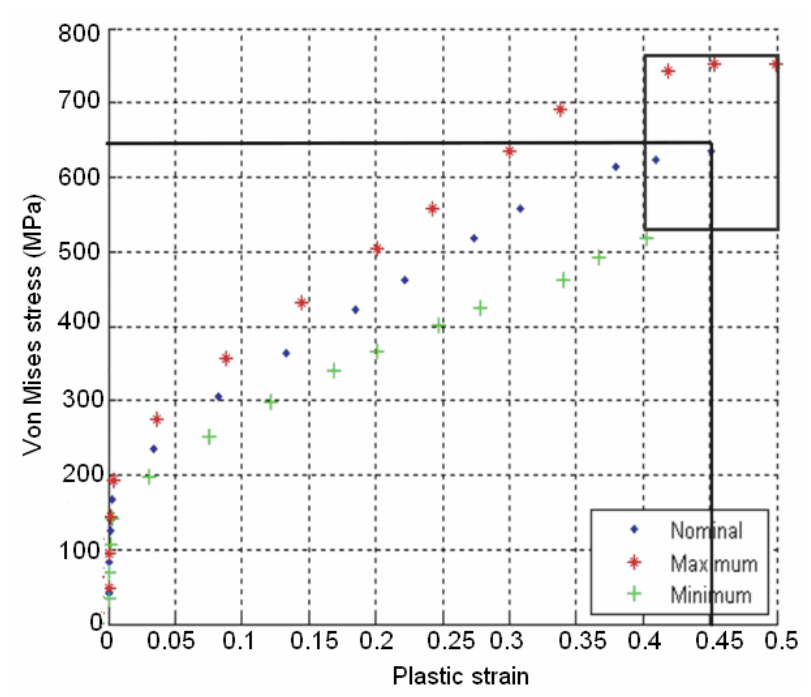

Figure 4: Nominal strain-stress curve and extreme points obtained by numerical simulations. The incertitude zone evaluated with the linear sensitivity analysis is represented by a rectangle

\section{REFERENCES}

[1] M. Koç, T. Altan: An overall review of the tube hydroforming (THF) technology, Journal of Materials Processing Technology 108:384-393, 2001.

[2] B. J. Mac Donald, M.S.J. Hashmi: Near-net-shape manufacture of engineering components using bulge-forming processes: a review, Journal of Materials Processing Technology 120:341-347, 2002.

[3] L. H. Lang, Z.R. Wang, D.C. Kang, S.J. Yuan, S.H. Zhang, J. Danckert, and K. B. Nielsen: Hydroforming highlights: sheet hydroforming and tube hydroforming, Journal of Materials Processing Technology 151:165-177, 2004.

[4] Yeong-Maw Hwang, Yi-Kai Lin, Taylan Altan: Evaluation of tubular materials by a hydraulic bulge test, International Journal of Machine Tools \& Manufacture 47:343-351, 2007.

[5] S. Fuchizawa, M. Narazaki: bulge test for determining Stress-Strain characteristics of thin tubes, Advanced Technology of Plasticity, Proceedings of the Fourth International Conference on Technology of Plasticity: 488-493, 1993.

[6] J. Slota, E. Spisak: Determination of flow stress by hydraulic bulge test, Metalurgija 47:1, 13-17, 2008.

[7] R. Velasco, N. Boudeau, Tube bulging test: Theoretical analysis and numerical validation, Journal of Materials Processing Technology 205: 51-59, 2008. 